\title{
Toward an analytical approach to studying the design characteristics of heritage buildings: a comparative analytical study of dome characteristics among the Islamic regions
}

\author{
A. Al-Mosawi ${ }^{1,2}$ \\ ${ }^{1}$ TU Dortmund University, Germany \\ ${ }^{2}$ Kufa University, Iraq
}

\begin{abstract}
The interest in this topic comes as part of the modern trends to study the architectural heritage of nations. Most of the studies that interpreted the Islamic heritage architecture had a high degree of generalization and narrative approaches that called for precise studies concerned with the main characteristics, patterns and the prevailing shapes amongst different regions and periods. This study attempts to develop an analytical approach by studying the design characteristics of a specific element and discovering its evolution and spread in different cultures, regions and periods. The dome was selected for the study because it represents a symbolic element in different civilizations and conduction of a comparative study identified the design characteristics in these regions. The study adopted a quantitative analysis approach to data collection and data analysis. The developed analytical framework can be employed for different architectural elements or functional types.

Keywords: dome, dome in Islamic architecture, Islamic regions, heritage architecture, design characteristics, design variables.
\end{abstract}

\section{Introduction and objectives}

This study is an extension to studies concerned with approaches to studying design characteristics of heritage architecture. The dome has been chosen for the study because it has its importance as an architectural and structural element that is dual in nature [1] and has been associated with symbolic meanings in Islamic 
architecture. This is from one point. The other point is to form a database of studying design characteristics of domes or other elements.

Many of the old and new architectural strategies depended on the approach of discovering the design characteristics of previous trends then criticizing them in order to repeal or modify them as a design strategy. Mitchell [2] points to the presence of three classifications in the field of architectural studies:

- Construction world: the architecture is built and actually presents in reality and which is affected by environment and use.

- Design world: it is the stage before the construction includes the architectural drawings and other means of presentation.

- Critical language world: architectural literature as intellectual means, studies, and research, this by the ordinary language of communication or by analysis or statistics or computer programs.

In the process of criticism we move from the construction world to the other parts while in the process of designing it is in reverse from theory to implementation. The methods of critical language were adopted in the current research as it leads us to understand the constructed architecture and derive a number of rules and guidelines that help in preparing future design strategies.

Bonta [3] defines two states that determine the characteristics of an architectural form or element:

1. Physical (morphological) characteristics: these are the characteristics that can be directly sensed like shape, color, finishing and textures.

2. Abstract characteristics: these are related to the perception by understanding architecture as a language; this includes characteristics of the form, space and the deeper perception characteristics like ratios and proportions.

To study any architectural work or element it is important to follow appropriate analysis methods. Through analysis the element to its components then giving names and identifying the physical and compositional characteristics between these parts [2]. The current study adopted this approach to identify the design characteristics of domes to build the analysis framework.

\subsection{Fractionation approach in studying the characteristics}

These are the steps involved in analyzing any element [2]:

1. Fractionation to parts: an analytical process that aims to perceive the nature of architectural work by splitting the element into parts to define the object.

2. Definition of physical characteristics of parts: determining the physical characteristics. These are shape, volume, mass, color, texture, material etc.

3. Definition of compositional relation between parts: These are of two types:

Dimensional relations: studying the dimension characteristics of an architectural object, by use of statistical methods to calculate their connections.

Compositional relations: studying the relations in a non-dimensional manner, either in two dimensions (plans or elevations) or three dimensions (building).

4. Expressing architectural characteristics by three methods [2]:

- Ordinary language: the method of the majority of literature. 
- Logic sentences: by the use of symbols, more like mathematical processes.

- Database: a number of constants which are the base of the study tables. The other information is entered as variables and values. This is a simple and efficient method of studying a certain element.

\section{Methodology and research design}

The study aimed to develop a systematic approach in studying heritage architecture characteristics and how these characteristics spread between different civilizations and periods.

The research referred to the dome design characteristics as (variables). Analysis of the dome variables will be in two levels as a separate element (part 1) and then for its relation to the whole composition or building (part 2), figure 1 shows the research structure.

The dome variables depend on analyzing the dome to its parts and the compositional relations between these parts and relation between dome and building. This passage points to important aspects for the comparative study:

The type of measurement: low sensitive quantitative measures by defining the values of variables.

The data collection methods: depending on literature that described and analyzed Islamic heritage in the form of figures, diagrams, photos and sketches.

The variables are divided into physical (morphological) and compositional and each has its own values, according to the architectural literature.
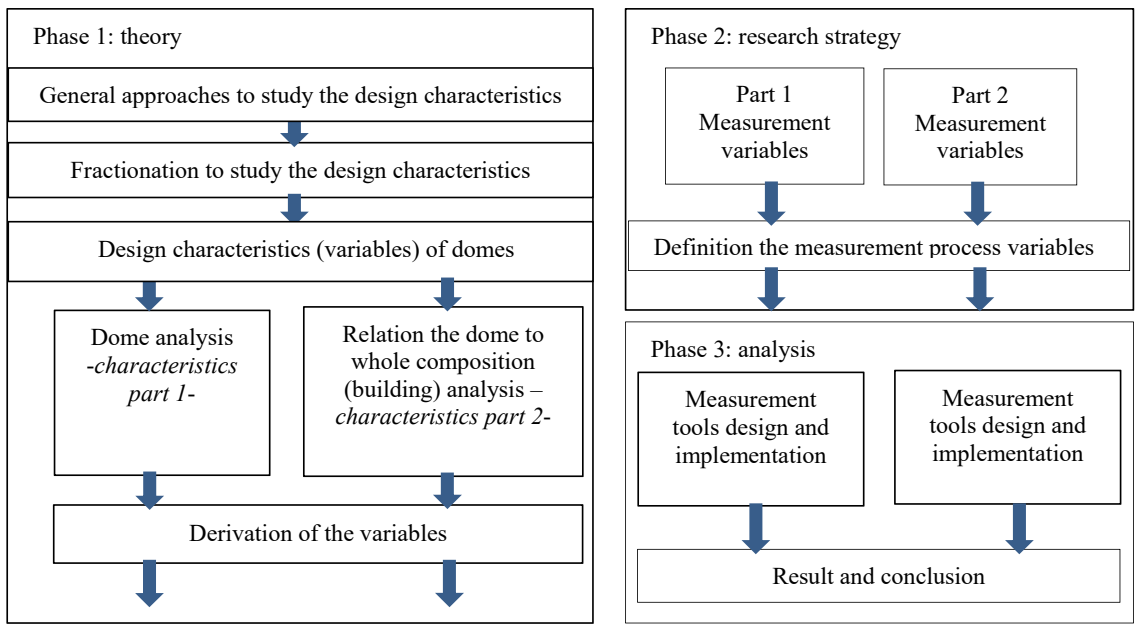

Figure 1: Research structure. 


\subsection{Definition and measurement of the variables of part 1}

\subsubsection{Definition of variables}

Determination of the variables of dome analyses as a separate element can be extracted as shown below:

Physical-morphological variables: this involves fractionation of the dome to the parts and defining the physical characteristics of these parts. During analyzing the dome it is seen to be composed of key and secondary parts [4].

These parts and the aspects to study their characteristics are:

- Transition tier: to transfer from the square shapes of load bearing system into the circular form of dome base. Study aspects: type, construction material, finishing material, secondary elements.

- Base: study aspects: shape of horizontal section, construction material, finishing material for interior and exterior surface, secondary elements.

- Drum (ring): is a cylinder form which the shell is rested on. Study aspects: shape of horizontal section, construction material, finishing material for interior and exterior surface, secondary elements.

- Shell: the space provided by the shell. Study aspects shape of vertical section, construction material, finishing material for interior and exterior surface.

- Summit (top cover): additional element in the top of dome. Study aspects: type, area of connection with the body.

Compositional variables: these are the compositional relations between the dome parts to each other. which can be expressed in abstract dimensionless drawings (figure 2).

Quantitative variables: these are the dimensional characteristics and were neutralized in the study. The measurement by using one of the measuring tools for available vertical sections, horizontal plans and the elevations in the literature or by field measurements and site documentation for the cases.

\subsubsection{Measurement of variables}

Measurement of dome variables as follows:

First: measurement of morphological variables, that depends on the type of variable and its defining features. Includes three types of values:

- Presence or absence of the variable within the dome (measured by yes/no).

- The defining feature of the variable (e.g. the type of transition tier defined by the type, vertical section defined by the shape of arch [1] etc.)

- Location of the variable within the dome.

Table 1 illustrates the measurement method. The results will allow us to notice the dominant or non-dominant features of each region.

Second: measurement of compositional variables: Includes measuring the relation of dome parts with each other, depending on the shape grammar concepts. The study focused on the essential parts in the dome:

Transition tier - base - drum (ring) - shell (dome body) - the top cover

The measurement method was in the form of separate dimensionless characteristic tables. Figure 2 illustrates the adopted form to analyze the dome section by drawing the sections of these parts. This analysis aims to know the 
degree of continuity of the characteristics of dome parts for each region and the variance among the regions.

Table 1: The adopted form to study the morphological characteristics of domes (source: author).

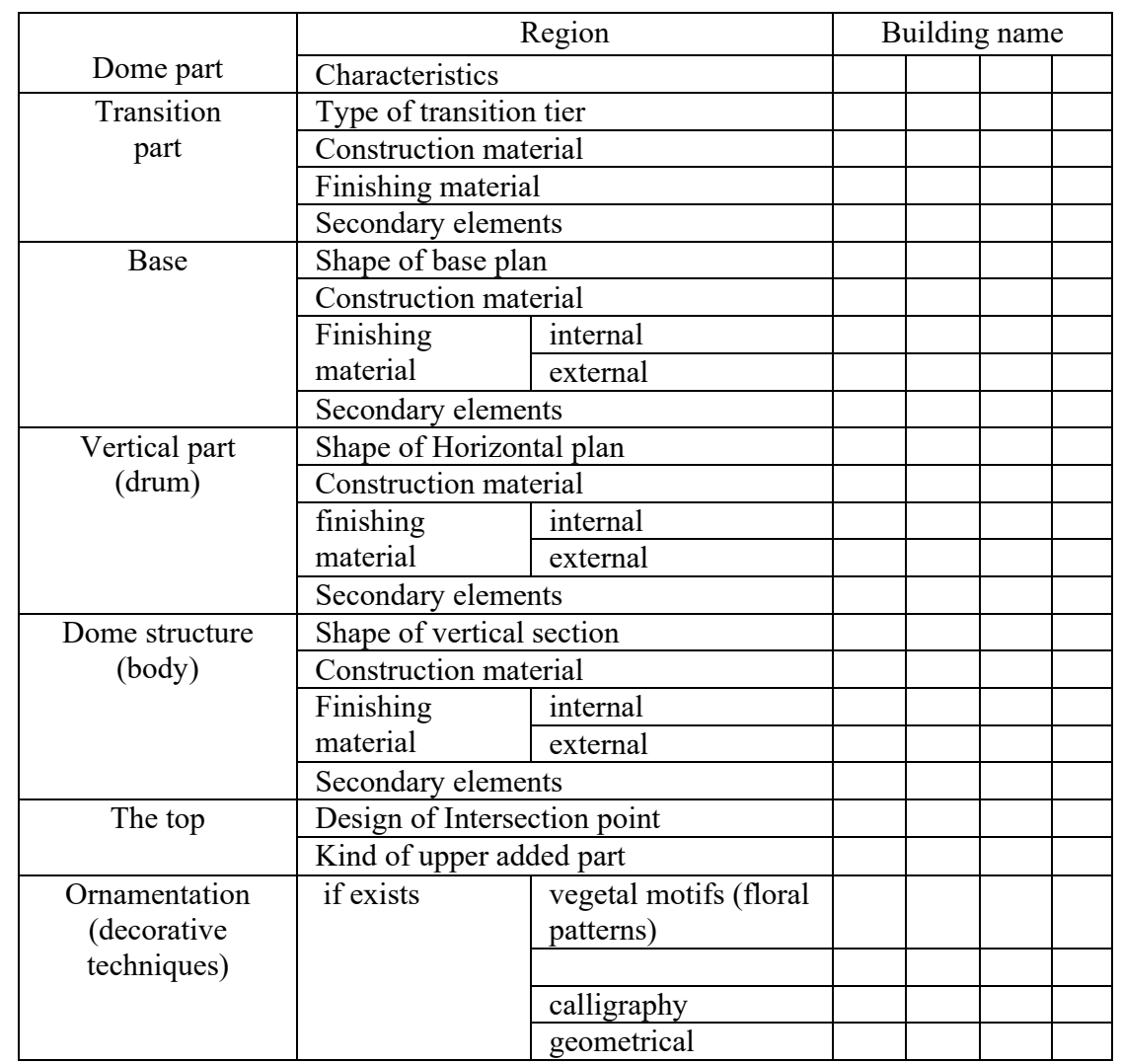

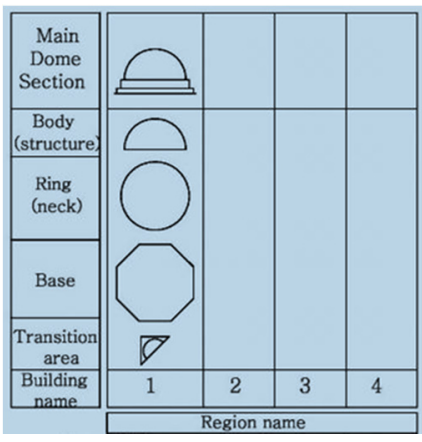

Figure 2: The compositional analysis model to the dome parts (source: author). 


\subsection{Definition and measurement of the variables of part 2}

\subsubsection{Definition of variables}

They include variables of relation between dome and the whole building:

First: definition of physical variables: the relation between physical form of dome and physical form of all building. In current research these variables related to the relation extent between dome and mosque:

1. Relation extent of dome to prayer hall: there are two variables, the numbers of main domes in prayer hall and location of dome/s in main hall.

2. Relation extent of dome to the minaret: one variable, location of dome/s to minaret/s.

3. Relation extent of dome/s to the main entrance: one variable, relation of main entrance axis with center of main dome/s.

4. Relation extent of main hall to the mosque: the location of the prayer hall to the whole composition, it may occupy a small space or the whole space.

Second: definition of spatial variables: the relations between the dome space (prayer hall in mosque) and other spaces in building. The variables here related to the connection extent of main hall (dome space) with the other spaces:

5. Relation extent between prayer hall and the building: two variables.

- Conformity in shape of main hall with the building mass.

- Correspondence of axis direction of important space with the building mass.

6. Relation extent of main hall with the main motion: one variable

- Direction of axes and its correspondence between main hall and the main motion.

7. Relation extent of prayer hall to the internal visual axis of the building:

- Matching of direction of visual axes in the main space and the building.

8. Relation extent of prayer hall entrance to the building elevation and center of dome: one variable available - location of prayer hall main entrance in relation to location of the dome and to the shape of the building.

9. Relation extent of entrance direction with dome space: one variable

- Direction of movement in main hall entrance.

10. Relation extent of prayer hall with the main entrance: one variable

- Matching degree of axis of main hall with the axis of main entrance.

11. Relation extent of prayer hall with the courtyard: three variables; visual relation, spatial relation and juxtaposition relation.

\subsubsection{Measurement of variables}

The method of measurement illustrated in form 1. Tables 2 and 3 illustrate the variables and their possible values. These depended on architectural literature that mentioned them directly or indirectly.

Measurement of physical variables: the measurement was conducted by defining the values of characteristics which were mentioned above. This is illustrated below in the following sequence: characteristic (variable): values as illustrated in tables 2 and 3 . 


\begin{tabular}{|l|l|l|}
\hline \multirow{2}{*}{ No. } & region & \\
\cline { 2 - 3 } & building name & \\
\hline & building location & \\
\hline Variable & variable name & \\
\hline No. & variable value & \\
\hline
\end{tabular}

The numbers of these forms depends on the numbers of variables.

Form 1: Physical and spatial variable measurement of part 2 (source: author).

1. Variable 1: number of domes within main hall: values $=$ one dome, two domes (equal or unequal in volume), three or more domes (equal or unequal).

2. Variable 2: location of dome/s within main hall: values $=$ central or noncentral, at the top or at the back of main hall or both, random domes, on the sides, in a matrix above the main hall.

3. Variable: the location of dome/s to minaret/s: values: no relation, central (in one axis), non-central (not in one axis).

4. Variable: the matching degree between the axis of entrance and the center of main dome/s: values $=$ (matching, not matching $)$.

5. Variable: the relation of prayer hall with the whole building: values = prayer hall is the whole composition, in one center, not on the same center (on the middle axis, on one sides of building).

Measurement of spatial variables: comprised of seven types of relations as in the following:

6. Variables: relation of prayer hall characteristics with the building characteristics: values: according to the shape (matching, not matching) and direction of axes (matching, not matching).

7. Variable: the direction of the axes between prayer hall and the main motion: values $=$ (matching, not matching).

8. Variable: the degree of matching between the visual axis of main hall and the visual axes of the building: values = (matching, not matching).

9. Variable: the relation of prayer hall entrance to center of dome: values $=$ (in one center, on both sides of center axis, entrance in another direction).

10. Variable: the relation of movement direction in main hall and main entrance: Values are (straight, broken, curved).

11. Variable: matching degree of the main hall axis and main entrance axis: Values $=$ (matching, not matching).

12. Relation of the main hall with courtyard: three variables: visual relation: values (not present, direct, indirect)/spatial relation: values (not present, direct, indirect, across another space)/juxtaposition relation: values (juxtaposition with access, juxtaposition with no access). 
Table 2: Variables and values of measurement process of part 2 (physical variables) (source: author).

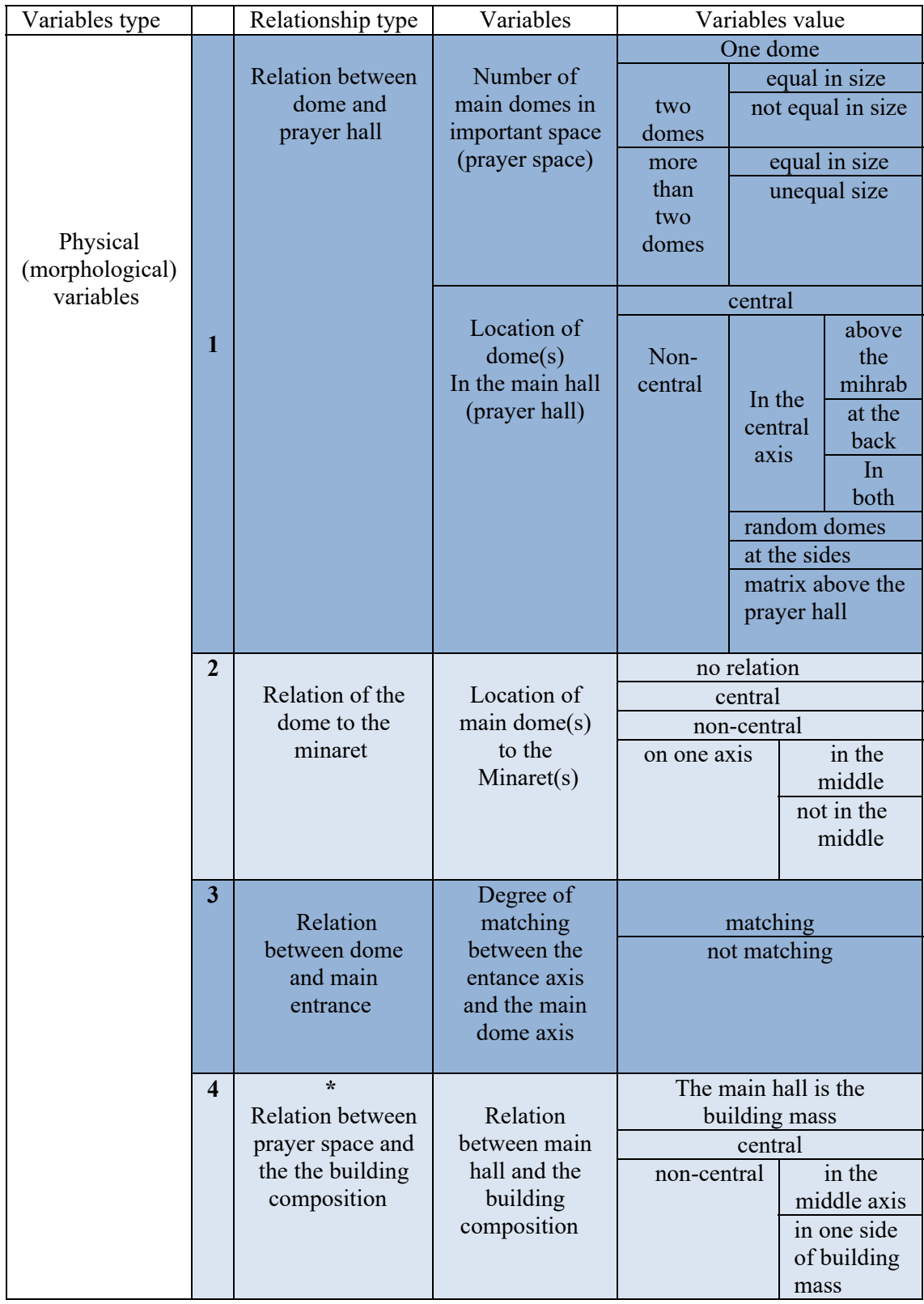


Table 3: Variables and values of measurement process of part 2 (spatial variables) (source: author).

\begin{tabular}{|c|c|c|c|c|c|}
\hline $\begin{array}{l}\text { Variables } \\
\text { type }\end{array}$ & & Relationship type & Variables & \multicolumn{2}{|c|}{ Variables value } \\
\hline \multirow{25}{*}{$\begin{array}{c}\text { Spatial } \\
\text { variables }\end{array}$} & \multirow[t]{4}{*}{5} & \multirow{4}{*}{$\begin{array}{l}\text { ** } \\
\text { Relation between } \\
\text { characteristics of } \\
\text { important space and } \\
\text { characteristics of the } \\
\text { building mass }\end{array}$} & \multirow{2}{*}{$\begin{array}{l}\text { in the form } \\
\text { aspects }\end{array}$} & \multicolumn{2}{|c|}{ identical } \\
\hline & & & & \multicolumn{2}{|c|}{ non identical } \\
\hline & & & in the axes & \multicolumn{2}{|c|}{ axes matching } \\
\hline & & & $\begin{array}{l}\text { direction } \\
\text { aspects }\end{array}$ & \multicolumn{2}{|c|}{ axes not matching } \\
\hline & \multirow[t]{2}{*}{6} & \multirow{2}{*}{$\begin{array}{l}\text { Relation between the } \\
\text { main space (Al harm) } \\
\text { and the main } \\
\text { movement axis }\end{array}$} & \multirow{2}{*}{$\begin{array}{l}\text { The direction } \\
\text { of axes and } \\
\text { their } \\
\text { conformity }\end{array}$} & \multicolumn{2}{|c|}{ identical } \\
\hline & & & & \multicolumn{2}{|c|}{ non identical } \\
\hline & \multirow[t]{2}{*}{7} & \multirow{2}{*}{$\begin{array}{l}\text { Relation between the } \\
\text { prayer space and } \\
\text { Internal visual axis of } \\
\text { the building }\end{array}$} & \multirow{2}{*}{$\begin{array}{l}\text { maching } \\
\text { degree of } \\
\text { visual axes } \\
\text { directions } \\
\end{array}$} & \multicolumn{2}{|c|}{ matching } \\
\hline & & & & \multicolumn{2}{|c|}{ not matching } \\
\hline & \multirow[t]{3}{*}{8} & \multirow{3}{*}{$\begin{array}{l}\text { Relation between the } \\
\text { main space (Al Harm) } \\
\text { entrance and the } \\
\text { centre of dome }\end{array}$} & \multirow{3}{*}{$\begin{array}{l}\text { Location of } \\
\text { entrance to } \\
\text { axis of dome } \\
\end{array}$} & \multicolumn{2}{|c|}{ centrally located } \\
\hline & & & & \multicolumn{2}{|c|}{ on both sides of the axis } \\
\hline & & & & \multicolumn{2}{|c|}{$\begin{array}{l}\text { entrance is on the another } \\
\text { direction }\end{array}$} \\
\hline & \multirow[t]{3}{*}{9} & \multirow{3}{*}{$\begin{array}{l}\text { Relation between the } \\
\text { enter direction and the } \\
\text { dome space }\end{array}$} & \multirow{3}{*}{$\begin{array}{l}\text { movement } \\
\text { direction on } \\
\text { the prayer hall } \\
\text { entrance }\end{array}$} & \multicolumn{2}{|c|}{ straight } \\
\hline & & & & \multicolumn{2}{|c|}{ refracted } \\
\hline & & & & \multicolumn{2}{|c|}{ oblique(indirect) } \\
\hline & \multirow[t]{2}{*}{10} & \multirow{2}{*}{$\begin{array}{l}\text { Relation of the main } \\
\text { space (prayer space) } \\
\text { with the main } \\
\text { entrance }\end{array}$} & & $\mathrm{ma}$ & ing \\
\hline & & & $\begin{array}{l}\text { degree of } \\
\text { prayer space } \\
\text { axis with the } \\
\text { main entrance } \\
\text { axis } \\
\end{array}$ & not $n$ & ching \\
\hline & 11 & & & visual & no relation \\
\hline & & Relation of prayer & Nature and & & direct \\
\hline & & space and central & value of & & indirect \\
\hline & & courtyard & relation & spatial & no relation \\
\hline & & & & & direct \\
\hline & & & & & $\begin{array}{l}\text { through the } \\
\text { other space }\end{array}$ \\
\hline & & & & & indirect \\
\hline & & & & juxtaposition & $\begin{array}{l}\text { adjacent and } \\
\text { permeability }\end{array}$ \\
\hline & & & & & $\begin{array}{l}\text { adjacent and } \\
\text { not } \\
\text { permeability }\end{array}$ \\
\hline
\end{tabular}

*The building mass and composition reperesnt all the mosque parts.

**The axis of important space (Al Harm) reperesent the vertical axis on the Al Qebla wall. 


\section{Case study selection and implementation}

The practical part of the research included formulating a measurement model for comparative study to explore the similarities and differences in dome characteristics across the Islamic regions and implementation of the developed model in selected cases. This paragraph discusses the procedures of second part, which is divided into three stages:

First stage: definition of the adopted classification approach to the domes. Islamic architecture characterized by a lengthy time period and occupation of a wide geographical area. A wide range of classification approaches were adopted by researchers such as according to the geographical area, functional type, regional zones or historical periods [5]. The current research methodology adopted the architectural characteristics and geographical regions classifications. According to the research aims these two approaches are suitable to the current research methodology. It is noted from the literature that there are eight important regions; these regions are from the west to the east [6].

Maghreb (it includes Arabic Maghreb parts and Al Andulaus), Egypt, Yemen, Levant (Al Sham), Iraq, Turkey (including the Balkans), Iran (includes Afghanistan and Central Asia), India.

For the historical periods the study tried to choose the samples in relatively close time periods for each region to gain accurate results.

Second stage: determining the functional type of samples, to conduct the comparative analysis. The research adopted the Mosques, because they have distinctive and clear characteristics.

Third stage: the selected samples from elected regions distinguished by a clear architectural form and distinctive shape of domes. The research tried to choose samples within close time period to ensure accurate results and the selection depended on the following criteria:

1. The samples have a clear architectural form and the dome is an essential part of their external composition.

2. Availability of sufficient documents, plans, pictures, reports and any other important details to facilitate the analysis process.

3. The samples are characterized by architectural originality and have no considerable changes as a result of restoration and maintenance.

Based on that 3-4 samples were selected from each region to conduct the analysis and comparative study as shown in table 4.

The implementation was done by analysing the cases according to the current study method. The analysis tables of the first part are mentioned below and the results of the analysis tables of the second part are not mentioned here and it could be mentioned as appendixes in future studies. 
Table 4: The selected samples from regions.

\begin{tabular}{|c|c|}
\hline 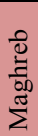 & $\begin{array}{l}\text { Great Mosque of Kairouan- AD } 863 \\
\text { Great Mosque of Zaytuna -AD } 856 \\
\text { Great Mosque of Sousse -AD } 851 \\
\text { Great Mosque of Mahdiya-AD } 916\end{array}$ \\
\hline 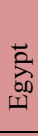 & $\begin{array}{ll}\text { Mosque of Sultan Qaytbay } & \text {-AD } 1474 \\
\text { Sultan Hassan Mosque } & \text {-AD } 1356 \\
\text { Mosque of Al-Mu'ayyad } & \text {-AD } 1415 \\
\text { Al-Sultan Al-Zahir Mosque } & \text {-AD } 1386 \\
\end{array}$ \\
\hline 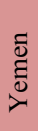 & $\begin{array}{ll}\text { Al Ashrafiya Mosque } & \text {-AD } 1295 \\
\text { Al Bakeria Mosque } & \text {-AD } 1597 \\
\text { Ta'hla Mosque } & \text {-AD } 1619 \\
\text { Al Jana Mosque } & \end{array}$ \\
\hline ב్ & $\begin{array}{ll}\text { Great Mosque of Damascus } & \text {-AD715 } \\
\text { Al-Aqsa Mosque } & \text {-AD1034 } \\
\text { Great Mosque of Hama } & \text {-AD1124 }\end{array}$ \\
\hline
\end{tabular}

\begin{tabular}{|c|c|}
\hline$\underset{\Xi}{\stackrel{\Xi}{\Xi}}$ & $\begin{array}{l}\text { Haider Khana Mosque } \\
\text { Al-Ahmadiya Mosque } \\
\text { Al Askari Mosque } \\
\text { Al Muradia Mosque }\end{array}$ \\
\hline 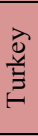 & $\begin{array}{ll}\text { Sehzade Mosque } & \text { - AD } 1548 \\
\text { Selimiye Mosque } & \text { - AD } 1574 \\
\text { Suleymaniye Mosque } & \text { - AD } 1558 \\
\text { Sultan Ahmed Mosque } & \text {-AD } 1616 \\
\end{array}$ \\
\hline 苂 & $\begin{array}{ll}\text { Jameh Mosque of Yazd } & -14^{\text {th }} \text { century } \\
\text { Goharshad Mosque } & - \text { AD } 1418 \\
\text { Sheikh Lotfollah Mosque } & - \text { AD } 1619 \\
\text { Shah Mosque } & - \text { AD } 1629\end{array}$ \\
\hline 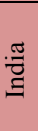 & $\begin{array}{ll}\text { Moti Masjid Agra } & \text { - AD } 1654 \\
\text { Moti Masjid Delhi } & \text { - AD } 1660 \\
\text { Jama Masjid, Delhi } & \text {-AD } 1656 \\
\text { Badshahi Mosque } & \text { - AD } 1673\end{array}$ \\
\hline
\end{tabular}

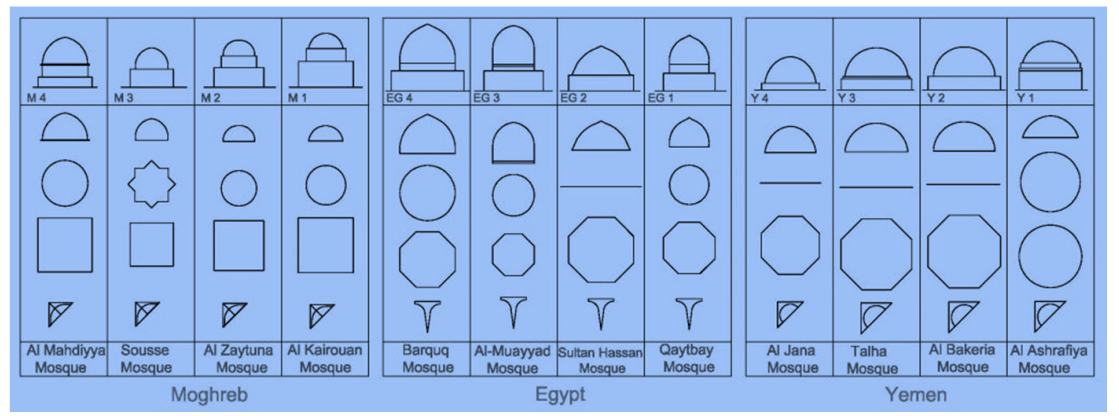

(1)

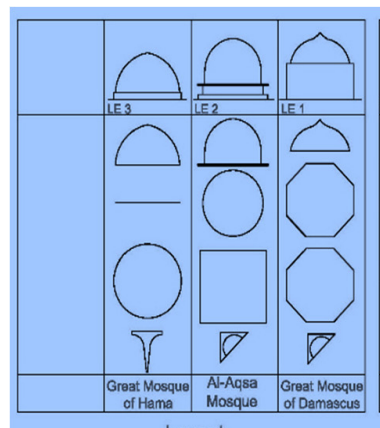

Levant

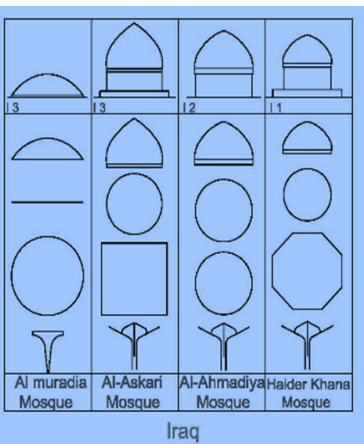

(2)

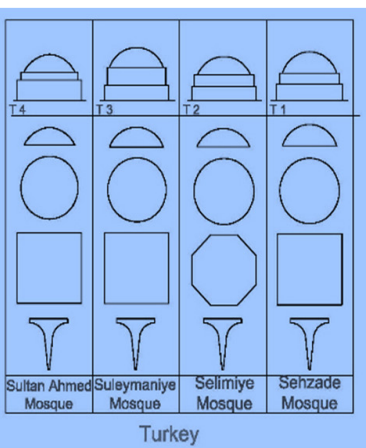

Turkey

Figure 3: The analysis of compositional variables of samples for each region (source: author). 


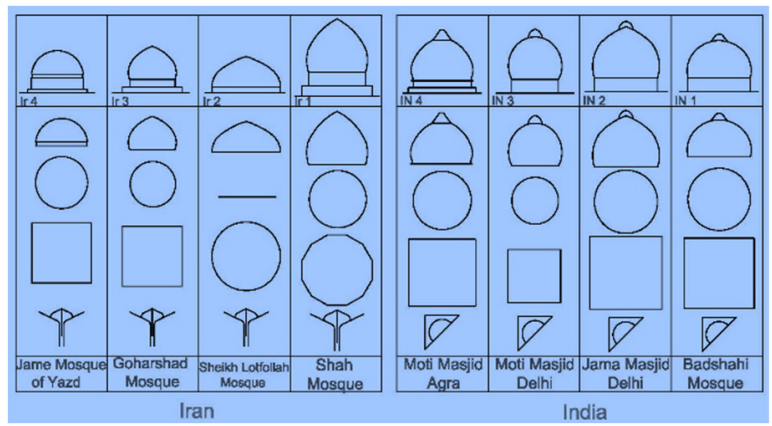

(3)

Figure 3: Continued.

\section{Results: discussion and conclusions}

The general conclusions focus on effectiveness of the previous architectural knowledge in building the theoretical framework of research as well as the effectiveness of this framework in revealing the differences in architectural characteristics among the Islamic regions. The review of previous studies revealed that the majority were descriptive, documentary and a few of them analytical. The research adopted analytical approaches to study the characteristics of elements and rules of form synthesis to study the relation between element parts.

The developed framework defines the main aspects in studying the dome and the proposed measurement tools for these aspects by adopting some of the previous analytical approaches besides the proposed approach. This framework can be used to demonstrate the differences among various regions and this can be utilized in defining the architectural identity.

\subsection{Practical study conclusions}

By implementation the model, the variances and similarities in dome characteristics among the regions were demonstrated and the uniqueness of each region could be highlighted. The conclusions divided into two types:

\subsubsection{The analysis of dome as a separate element (part 1)}

1. The selected regions shared general characteristics, which influenced spread of the Domes in the Islamic architecture, in addition to the secondary characteristics that gave an identity to each region.

2. Results showed an obvious difference among the regions regarding the physical characteristics of the dome in external and internal form.

3. It was observed that the samples of each region were interconnected in the physical form and spatial characteristics. This contributed to formation of their identity and uniqueness. 
4. The importance of dome in the physical form was observed in a downgrade trend from the eastern to the western regions. That was most obvious in the regions (India, Turkey, Iran, Iraq and Egypt).

5. The construction techniques, material and finishing were subjected to the available material in each region, by this uniqueness was also achieved.

The regions (Turkey, India, Yemen, Levant (Al Sham), Maghreb) had no decorations on the exterior surfaces of domes; the regions (Iran, Iraq, and Egypt) had variable decorations on the exterior surfaces.

6. The results showed that the dome was an essential element in the mosques and appeared earlier in the regions (Maghreb, turkey, India, Iran and Egypt) and those they had authenticity and were not much influenced by other regions. On the other hand the dome appeared later on in regions (Iraq, Yemen, and Levant) as a result of external influences that stemmed from the cultural influences.

7. The distinguishing features for each region were divided into essential and secondary. The essential demarcated the general similarity of the domes within the regions and the secondary determined the regional uniqueness. These characteristics take shape and be complete the more one goes from west to east.

8. The vertical section of the dome was the important feature, whereby its distinctive form gave the variance and uniqueness. This is affected by the era, the materials and the building function. The regions (Maghreb, Egypt, turkey, Iran, India) are characterized by distinctive differences between the shapes of their domes. The domes in Iraq region had similar characteristics to Iran region meanwhile the regions (Levant, Yemen) had no clear distinctions.

9. The majority of the regions achieved an obvious continuity and integration in the compositional hierarchy of dome parts. The regions can be arranged according to degree of compositional rules in the following way (India, turkey, Maghreb, Egypt, Iran, Iraq, Levant and Yemen).

10. The regions could be arranged according to the space size that is roofed by the dome in the following; (Turkey, India, Iran, Iraq, Egypt, Levant, Yemen, and Maghreb).

\subsubsection{The relation of the dome to the building (part 2)}

Two main groups of conclusions were defined:

\section{First group:}

1. The variation in physical characteristics of domes is larger than the variation in the spatial characteristics. That is due to the stability of the spatial characteristics of dome space - main hall and its continuity among the regions

2. No general similarities among the regions were identified.

3. Many of the related variables showed a resemblance in most of the regions, that was achieved in the variables first, second, fifth, eighth, ninth and eleventh. 
4. Variation was shown between two groups (that are similar) in four variables which are the third, sixth, seventh and tenth.

5. The variation was not separate for each region, but occurred in large or small groups of regions that had comparable characteristics

6. Some regions had no clear distinguishing features in some variables as a groups or individually such as: Variable 1 [Egypt]/Variable 2 [Egypt, Levant, Iraq and Yemen]/Variable 3 [Egypt]/Variable 4 [Iraq,Yemen, Levant and Egypt]/Variable 5 [Egypt]/Variable 6 [Yemen and Levant]/Variable 7 [Yemen and Levant)]/Variable 8 [Egypt]/Variable 10 [Yemen and Levant]/Variable 11 [Egypt]. It is obvious the factors that contributed to the similarity between the regions were more than these contribute in the differences between regions.

\section{Second group:}

The essential characteristics appeared in different values and show its importance in determining the identity and uniqueness of each region.

1. First variable represents the essential characteristic for most regions, its importance is concentrated in Turkey, India, Maghreb/fifth variable essential characteristic in Egypt/sixth variable essential in Iran, Iraq, and Egypt.

2. Second variable is an essential characteristic for some regions and nonimportant for others. Its importance was in Turkey, India, Maghreb/sixth variable is essential except Yemen and Levant.

3. Third variable is an essential characteristic for all regions except Egypt.

4. Fourth variable is essential for most regions within similar values.

\section{References}

[1] Alzubaidi, M., The Arch in Islamic Architecture. Architectural department, Baghdad University, Baghdad, p. 17, 1990.

[2] Mitchell, William J., The logic of architecture. The Mit press: Cambridge. Mass, pp. 3-71, 1992.

[3] Bonta, J., Notes on the theory of meaning in the design, John Wiley: New York, pp. 21-30, 1980.

[4] Ashkan, M. \& Ahmad, Y., Persian Domes: History, Morphology and Typologies. In ArchNet-IJAR: International Journal of Architectural Research, vol. 3, issue 3 (2009) pp. 98-115.

[5] Mounes, H., Mosques (in Arabic), The world of knowledge book series: Al Kuwait, 1981.

[6] Qasim, M., Design Characteristics in Islamic Architecture: study of Minarets. Architectural department, University of Technology, Baghdad, pp. 5-53, 1996. 